\title{
Development of open-set test in Marathi language for assessing speech identification performance of native children
}

\author{
S. B. Rathna Kumar*, Udit Saxena ${ }^{2}$, P. Phani Krishna ${ }^{3}$, Abhijeet Ramesh Shinde ${ }^{4}$, Ketaki Vinayak Borkar ${ }^{1}$

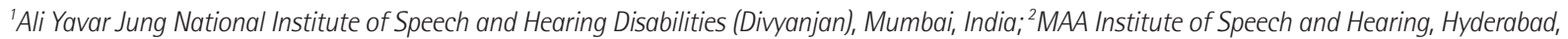 \\ India; ${ }^{3}$ Center for Neural and Cognitive Sciences, School of Medical Sciences, University of Hyderabad, Hyderabad, India; ${ }^{4}$ Atharva Speech and \\ Hearing Care Private Limited, Mumbai, India
}

Purpose: Speech identification score (SIS) testing has been used in every phase of the audiological test battery. We developed an open-set test in Marathi for assessing the speech identification performance of native children.

Methods: The development of the test took place in three phases which included the development of word lists, recording of word lists, and SIS testing. The developed test consisted of four word-lists with each list consisting of 15 monosyllabic words in CVC structure and 10 disyllabic words in CVCV structure. The recording was performed in a sound-treated room where ambient noise levels were maintained as per the permissible levels. SIS testing was performed on a total of 90 children with normal hearing who were equally divided into three groups. Groups I, II, and III consisted of children in the range between 6 and 6.11 years, 7 and 7.11 years, and 8 and 8.11 respectively.

Results: The data were subjected to one-way ANOVA and the results revealed no statistically significant difference ( $p>0.05$ ) in SIS between three groups for each word list and between four word-lists for each group. The overall groups' mean SIS were 99.15\%, 98.97\%, $99.06 \%$, and $99.02 \%$ for four word-lists respectively, and were falling within the normal range (90 to $100 \%$ ).

Conclusions: Findings of the present study are in line with the findings of research reports on other Indian languages. The four word-lists developed in the present study were found to be equally difficult, reliable, and valid test materials in Marathi for assessing native children.

Keywords: Open-set test, Monosyllabic words, Disyllabic words, Speech identification score, Marathi

\section{INTRODUCTION}

Understanding speech is a very important component of human communication. Good auditory integrity is required to hear and understand speech. Therefore, individuals with hearing impairment are more susceptible to difficulties in perceiving speech. Further, speech perception is a vital skill that provides valuable information about overall auditory perceptual skills and helps outline the prognosis of speech, language, and cognitive abilities of children. Thus, speech audiometry, which provides information about one's ability to understand speech is considered as an essential component of the audiological test battery [1,2].

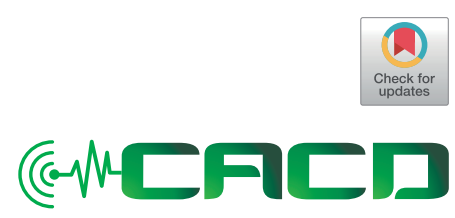

Received: May 12, 2020

Revision: September 7, 2020

Accepted: September 22, 2020

Correspondence:

S. B. Rathna Kumar

Ali Yavar Jung National Institute of Speech and Hearing Disabilities (Divyanjan), Bandra (west), Mumbai, India

Tel: +0918286157500

Fax: +22-26404170

E-mail: sarathna@yahoo.co.in

C 2020 The Korean Association of SpeechLanguage Pathologists

This is an Open Access article distributed under the terms of the Creative Commons Attribution NonCommercial License (https://creativecommons.org/ licenses/by-nc/4.0/) which permits unrestricted noncommercial use, distribution, and reproduction in any medium, provided the original work is properly cited. 
Two common speech audiometric measures are speech recognition threshold (SRT) and speech identification score (SIS). SRT is the threshold required for the identification of speech stimuli which is similar to the estimate of auditory sensitivity in pure-tone audiometry. SIS is the percentage of correct recognition of speech at the supra-threshold level under optimum listening conditions. SIS testing has been widely used in audiological test battery and the significance of this testing in diagnostic and rehabilitative purposes has been well documented [1]. SIS testing helps to describe the ability to understand speech as a function of the degree of hearing impairment, differentially diagnose auditory disorders, determine the need of various forms of aural rehabilitation devices, make comparisons in terms of benefits between various forms of aural rehabilitation devices, verify the benefits of usage of various forms of aural rehabilitation devices, and monitor child's performance over time for either diagnostic or rehabilitative purpose [1].

SIS testing must be evaluated routinely using valid and reliable clinical assessment procedures appropriate to a specific population. Various speech audiometry materials have been developed in English and other languages. Several materials for speech audiometry have also been developed in Indian languages. Marathi is a southern Indo-Aryan language and one of the 22 official languages of India. Marathi is the official language of Maharashtra and Goa. Marathi is the 3rd largest among the languages of India and the 10th largest among the languages of the world. Considering Marathi, Kumar et al., [3] developed an open-set speech identification test for assessing adults. This test consisted of four word-lists with each word list consisting of 25 words. The four word-lists developed in Marathi were found to be equally difficult, reliable, and valid materials for assessing speech identification performance of adult native speakers of Marathi.

The speech identification performance of children improves as the children's age progresses and eventually becomes comparable to the adult-like performance by the age of around 10 to 12 years on many speech-identification tests [1]. Open-set speech identification performance can be assessed in typically developing children by the age of six years. The speech identification performance of children mainly depends on the level of language development as well as the children's auditory capabilities. Therefore, while evaluating these children, it is important to use speech identification tests which include test words that are within the receptive and expressive language competencies of the children to obtain adult-like performance. Therefore, the open-set speech identification test available in Marathi [3] would be scientifically inappropriate when evaluating children under the age of 10 years because the test words were established by considering the speech and language competencies of adults, and would be challenging to children. The test words should therefore be familiar to children and within children's receptive and expressive abilities to achieve adult-like performance on speech identification tests.

Considering the growing implications of speech identification tests for diagnostic, rehabilitative, and research purposes, there is a need of developing speech identification tests for evaluating children under the age of 10 years. Hence, the present study aimed at developing an open-set speech identification test in Marathi for assessing children who are native speakers by considering test words that are known to them and are within their receptive and expressive vocabulary.

\section{METHODS}

The overall study was conducted in three phases. Phase I: Development of word lists in Marathi; Phase II: Recording of word lists; and Phase III: Speech identification score (SIS) testing.

\section{Development of Word Lists in Marathi}

The following steps were involved in the development of the word lists in Marathi for assessing the speech identification performance of children. Step I: Familiarity assessment of words; Step II: Content validity; and Step III: Construction of final word lists.

\section{Familiarity Assessment of Words}

The monosyllabic and disyllabic words in Marathi established by Kumar et al. [3] for developing speech identification test in Marathi for adults (unpublished) were subjected to familiarity assessment. This corpus consists of 427 monosyllabic words in CVC structure and 313 disyllabic words in CVCV structure. These words were considered to be most familiar to and commonly used by adult native speakers of Marathi [3]. These words were subjected to familiarity assessment to ensure that children knew the words and form their receptive and expressive vocabulary.

\section{Participants}

A total of 90 children in the age range between 6 and 8 years with normal hearing from some government schools in Ma- 
harashtra where Marathi is the medium of instruction served as participants. The participants were equally divided into three groups; Group I with children in the age range between 6 and 6.11 years, Group II with children in the age range between 7 and 7.11 years, and Group III with children in the age range between 8 and 8.11 years.

\section{Procedure}

Parents of the above children were involved in the familiarity assessment of words and formed three groups. An interview session was scheduled with each group of parents to explain the procedure of familiarity rating of words. The list of words was given to each group of parents and they were asked to rate these words in terms of familiarity considering their children's receptive and expressive vocabulary. A three-point rating scale was used for rating familiarity of words, i.e., most-familiar, familiar, and unfamiliar. Parents were explained about the familiarity ratings as follows; Most familiar: a word should be rated as 'most familiar' if your child knows the meaning of that word and he/she uses the same word to express in daily routine activities, Familiar: a word should be rated as 'familiar' if your child knows the meaning of that word but he/she uses an alternative word to express in daily routine activities, and Unfamiliar: a word should be rated as 'unfamiliar' if your child is not aware of the word. The parents were provided enough opportunity to clarify their doubts (if any) with the rating procedure in this session.

The parents were given one week to complete the familiarity rating. After the familiarity rating of words had been completed, another interview session was held with parents to review the parents' ratings. If the parents thought that they were still in doubt about the rating of any of the words, their concerns were further clarified. After clarifying the concerns of the parents, they were further given one day to complete the familiarity rating. The clarification helped to increase the accuracy of the familiarity rating. The authors scored the rating of parents. The words, which were rated as most-familiar, familiar and unfamiliar were assigned a score of 2,1 , and 0 respectively. A respective score was assigned for each word based on the parents' ratings. Word-wise scores based on ratings of parents were summed to obtain a word-wise total score for each group separately. The maximum score that could be obtained for each word from the ratings of parents of each group $(\mathrm{N}=30)$ was $60(2 \times 30=60)$. The word-wise total score was then converted to a percentage. For the purpose of the present study, the words with a $90 \%$ score and more were considered to be most appropriate for the construction of word lists. These words were listed separately for each group (three lists) and further assessed for homogeneity across three lists, i.e., the words with a score of $90 \%$ and more score, and present in all the three lists were only selected and listed separately for further assessment.

\section{Content Validity}

The words that were considered most appropriate for constructing word lists upon familiarity assessment were subjected to content validity. The content validity is based on the degree to which a measurement represents the specific and intended domain of interest. This form of validity is useful for examining the essential test items that can be attributed to the measurements. The logic and expertise are the driving forces for performing content validity. The list of words obtained after familiarity assessment was given to six experts who were practicing in the field of Speech-Language Pathology, Audiology, and Linguistics. The experts were informed about the purpose of the study and were asked to respond to whether the words selected would fulfill the purpose of the study. Their responses were elicited under the categories of agree, disagree, and suggestions. A word-wise validation was carried out by each expert. The words agreed by each expert were listed separately and further tested for homogeneity across six lists, i.e., the words agreed by each expert and present in all six lists were only selected and listed separately for final word list construction. While $90 \%$ and more criteria were considered during familiarity assessment, we considered $100 \%$ criteria for content validity to increase the appropriateness of test words.

\section{Construction of word lists}

A total of two word-lists were constructed with each word list consisting of 25 words. Each word list consisted of 15 monosyllabic words in CVC structure and 10 disyllabic words in CVCV structure. It was ensured that both the word lists have an equal distribution of consonant phonemes. Phonemes upon which the word lists were constructed were based on the frequencies of occurrence of consonant phonemes among monosyllabic and disyllabic words in Marathi [3]. Each list was randomized once to form a total of four word-lists, i.e., List 1, List 2, List 3 (Randomization of List 1), and List 4 (Randomization of List 2) (see Appendix).

\section{Recording of word lists}

The recording was done in a sound-treated room where noise 
levels were maintained as per the permissible levels. Each word list was spoken by an adult female native speaker of Marathi who is a professional voice user. The recording was carried out using a $16 \mathrm{kHz}$ sampling rate and 16-bit quantization and the signal was digitized at a sampling rate of $16 \mathrm{kHz}$ using a 12-bit analog to digital converter housed within the computer. Each word list was saved as a separate file. The recorded material was then edited to carry out noise and hiss reduction. Amplitude normalization of the signals was done using the adobe audition (version 3.0) software to maintain the constant amplitude across the words. The inter-stimulus interval between the two words was set to 5 seconds. A calibration tone of $1 \mathrm{kHz}$ was inserted before the beginning of the wordlist to adjust the VU meter at zero. The four word-lists were then copied onto an audio compact disc using a compact disc writer.

\section{Speech Identification Score (SIS) Testing \\ Participants}

A total of 90 children in the age range between 6 and 8 years with normal hearing from some government schools in Maharashtra where Marathi is the medium of instruction served as participants. The participants were equally divided into three groups; Group I with children in the age range between
6 and 6.11 years, Group II with children in the age range between 7 and 7.11 years, and Group III with children in the age range between 8 and 8.11 years. The audiological evaluations including otoscopic examination, pure-tone audiometry, and tympanometry were conducted to ensure that the subjects were suitable for the study.

\section{Procedure}

SIS testing was carried out in a sound-treated room where the noise levels were maintained as per the permissible levels. The stimulus was played through a CD player, which was routed through Digital Diagnostic Audiometer and delivered through the TDH 39 headphones. The stimulus was presented at 40 dBSL with reference to the pure-tone average (PTA) threshold as per the standard protocol. All the children were tested monaurally with four word-lists and the selection of ear was randomized. An open-set response in the form of an oral response was obtained. Each correct response was given a score of 1 and an incorrect response was given a score of 0 . The raw score was then converted to a percentage known as SIS.

\section{RESULTS}

The mean and standard deviation values of SIS obtained by

Table 1. Mean, SD, SE and Range of SIS (\%) of three groups for four word-lists

\begin{tabular}{|c|c|c|c|c|c|c|c|}
\hline \multirow{3}{*}{ Group } & \multirow{3}{*}{ Word list } & \multirow{3}{*}{$N$} & \multicolumn{5}{|c|}{ Speech identification score (\%) } \\
\hline & & & \multirow{2}{*}{ Mean } & \multirow{2}{*}{$S D$} & \multirow{2}{*}{$S E$} & \multicolumn{2}{|c|}{ Range } \\
\hline & & & & & & Minimum & Maximum \\
\hline \multirow[t]{4}{*}{ Group I } & List 1 & 30 & 98.53 & 01.96 & 0.3579 & 92.00 & 100.00 \\
\hline & List 2 & 30 & 98.27 & 02.02 & 0.3681 & 92.00 & 100.00 \\
\hline & List 3 & 30 & 98.40 & 01.99 & 0.3639 & 92.00 & 100.00 \\
\hline & List 4 & 30 & 98.13 & 02.03 & 0.3706 & 92.00 & 100.00 \\
\hline \multirow[t]{4}{*}{ Group II } & List 1 & 30 & 98.67 & 01.92 & 0.3502 & 96.00 & 100.00 \\
\hline & List 2 & 30 & 98.80 & 01.86 & 0.3404 & 96.00 & 100.00 \\
\hline & List 3 & 30 & 98.67 & 01.92 & 0.3502 & 96.00 & 100.00 \\
\hline & List 4 & 30 & 98.53 & 01.96 & 0.3579 & 96.00 & 100.00 \\
\hline \multirow[t]{4}{*}{ Group III } & List 1 & 30 & 98.93 & 01.80 & 0.3285 & 96.00 & 100.00 \\
\hline & List 2 & 30 & 98.67 & 01.92 & 0.3502 & 96.00 & 100.00 \\
\hline & List 3 & 30 & 98.80 & 01.86 & 0.3404 & 96.00 & 100.00 \\
\hline & List 4 & 30 & 99.07 & 01.72 & 0.3142 & 96.00 & 100.00 \\
\hline \multirow[t]{4}{*}{ Overall } & List 1 & 90 & 98.71 & 01.88 & 0.1981 & 92.00 & 100.00 \\
\hline & List 2 & 90 & 98.49 & 01.95 & 0.2055 & 92.00 & 100.00 \\
\hline & List 3 & 90 & 98.62 & 01.91 & 0.2014 & 92.00 & 100.00 \\
\hline & List 4 & 90 & 98.44 & 01.96 & 0.2067 & 92.00 & 100.00 \\
\hline
\end{tabular}

SD, standard deviation; SE, standard error. 
three groups and the overall group for four word-lists were calculated and depicted in Table 1. The data were subjected to one-way ANOVA to analyze the significant difference in mean SIS between within three groups for each word list, between and within four word-lists for each group, and between and within four word-lists for the overall group and depicted in Table 2 and Table 3.

The mean SIS of each group and overall group for four word-lists were falling within the normal range of SIS, i.e., 90 to $100 \%$. There was no statistically significant difference $(p>0.05)$ in mean SIS between and within three groups for each word list, between and within four word-lists for each group, and between and within four word-lists for the overall group.

\section{DISCUSSION}

The present study developed an open-set speech identification test in Marathi for assessing children by considering the test words which are within the receptive and expressive vocabulary of children. Hence, familiarity assessment among children with different age groups was carried out to ensure that the selected words form the receptive and expressive vocabulary of children. The words rated as 'most familiar' were listed for each age group separately and these words were further assessed for homogeneity across the groups to ensure that the selected words were known to children and were common in usage. These words were further subjected to content validity to review how essential these words can attri-

Table 2. One-way ANOVA results showing comparison of mean SIS (\%) between and within four word-lists for each group

\begin{tabular}{|c|c|c|c|c|c|c|}
\hline Group & & Sum of squares & $d f$ & Mean square & $F$ & Sig. \\
\hline \multirow[t]{3}{*}{ Group I } & Between word lists & 2.667 & 3 & 0.889 & 0.222 & 0.881 \\
\hline & Within word lists & 464.000 & 116 & 4.000 & & \\
\hline & Total & 466.667 & 119 & & & \\
\hline \multirow[t]{3}{*}{ Group II } & Between word lists & 1.067 & 3 & 0.356 & 0.097 & 0.962 \\
\hline & Within word lists & 425.600 & 116 & 3.669 & & \\
\hline & Total & 426.667 & 119 & & & \\
\hline \multirow[t]{3}{*}{ Group III } & Between word lists & 2.667 & 3 & 0.889 & 0.266 & 0.850 \\
\hline & Within word lists & 387.200 & 116 & 3.338 & & \\
\hline & Total & 389.867 & 119 & & & \\
\hline \multirow[t]{3}{*}{ Overall } & Between word lists & 4.044 & 3 & 1.348 & 0.363 & 0.779 \\
\hline & Within word lists & $1,320.356$ & 356 & 3.709 & & \\
\hline & Total & $1,324.400$ & 359 & & & \\
\hline
\end{tabular}

Table 3. One-way ANOVA results showing comparison of mean SIS (\%) between and within three groups for each word list

\begin{tabular}{|c|c|c|c|c|c|c|}
\hline Group & & Sum of squares & $d f$ & Mean square & $F$ & Sig. \\
\hline \multirow[t]{3}{*}{ List I } & Between groups & 2.489 & 2 & 1.244 & 0.347 & 0.708 \\
\hline & Within groups & 312.000 & 87 & 3.586 & & \\
\hline & Total & 314.489 & 89 & & & \\
\hline \multirow[t]{3}{*}{ List II } & Between groups & 4.622 & 2 & 2.311 & 0.618 & 0.541 \\
\hline & Within groups & 325.333 & 87 & 3.739 & & \\
\hline & Total & 329.956 & 89 & & & \\
\hline \multirow[t]{3}{*}{ List III } & Between groups & 2.489 & 2 & 1.244 & 0.336 & 0.716 \\
\hline & Within groups & 322.667 & 87 & 3.709 & & \\
\hline & Total & 325.156 & 89 & & & \\
\hline \multirow[t]{3}{*}{ List IV } & Between groups & 3.156 & 2 & 6.578 & 1.806 & 0.706 \\
\hline & Within groups & 316.800 & 87 & 3.641 & & \\
\hline & Total & 329.956 & 89 & & & \\
\hline
\end{tabular}


bute to the test measures. Content validity was carried out by six experts working in the field of Speech-Language Pathology, Audiology, and Linguistics. The words which were found essential by all the experts were listed separately. These words served as the foundation for constructing final word lists for assessing the speech identification performance of children in Marathi.

The concept of phonemic balance played a major role in the development of speech identification tests. The phonemic balancing implies that the phonemes in the word list occur with the same relative frequency as they do occur in a representative sample of speech of a particular language [4]. The phonemically balanced word lists are a long-established tool for assessing speech identification performance. However, the phonemic balance has been appeared to have an inadequate practical influence on the outcome measures of speech identification tests, and its clinical significance is also questionable. Speech identification performance of individuals with hearing impairment or normal hearing did not appear to be affected by whether the word list had a phonemic balance or not [5]. Hence, the issue of phonemic balance is still an area of argument in terms of its significance in speech identification testing. However, to avoid the bias of the distribution of phonemes and have an equal degree of distribution of phonemes in each word list, we felt that phonemic balance is important at least for consonants. A similar argument was made by Kumar \& Mohanty [6] while developing a speech identification test in Marathi for adults. The consonantal aspect of phonemic balance is important as the perception of consonants is much more complex than vowel perception due to their low intensity, more susceptible to degradation, and varied classifications $[6,7]$. Hence, we also considered this aspect of phonemic balance is reasonable in the present study.

A total of two word-lists were constructed with each word list consisting of 25 words. Each word list consisted of 15 monosyllabic words in CVC structure and 10 disyllabic words in CVCV structure. Each list was randomized once to form a total of four word-lists i.e., List 1, List 2, List 3 (Randomization of List 1), and List 4 (Randomization of List 2). This was done because more than one form of the same test is usually required. After all, more than one administration is almost always necessary under experimental or clinical conditions. A limited number of word lists upon multiple administrations of the same items in the same order will affect the test findings due to order and practice effects. Hence, several equivalents and alternative forms of the same tests are needed so that subject's performance is not a reflection of their ability to remember the speech stimuli, rather, their performance in the recognition of the speech stimuli [8]. It was ensured that all the word lists have an equal distribution of consonant phonemes. The phonemes upon which the word lists were constructed were based on the frequencies of occurrence consonant phonemes in Marathi among monosyllabic words in CVC structure and disyllabic words in CVCV structure in Marathi as reported by Kumar et al. [3]. In Marathi, the letter “च” represents [t] and [ts], and the letter "ज" represents [dz] and $[\mathrm{dz}]$. However, there are no separate letters for $[\mathrm{t}]$ and $[\mathrm{ts}]$, and $\left[\mathrm{d}_{3}\right]$ and $[\mathrm{dz}]$ in Marathi. The phonemes $[\mathrm{g}]$ and $[\mathrm{ts}]$ are represented by the letter "च" and the phonemes [dz] and [dz] are represented by the letter "ज". Hence, they are represented as "च" and "ज" in the word lists.

Speech identification performance must be assessed routinely using reliable and valid materials suitable for native speakers of the concerned language to ensure that the measure accurately reflects the behavior of interest. Reliability refers to the extent to which measurements are repeatable by the same individual using the same measures of a particular attribute, by the same individual using different measures of the attribute, or by different people using the same measure of the attribute without the interference of error [9]. In the present study, the equivalence analysis of four word-lists was carried out to check the reliability of developed word lists and to ensure that the four word-lists must be equally difficult so that the children's speech identification performance obtained on one word-list is similar to the performance of the same group of children on another word list. On the other hand, to ensure that the children of different groups obtain similar speech identification performance on the same word list. It was found that there was no statistically significant difference $(p>0.05)$ in speech identification performance between four word-lists for each group. Similarly, there was no statistically significant difference $(p>0.05)$ in speech identification performance between the three groups for each word list. Hence, the four word-lists developed were found to be reliable and equally difficult. These word lists can be used interchangeably for any group of children in clinical practice.

The extent to which a test appears to measure what it is supposed to measure constitutes validity [9]. We performed criterion-related validity to check the validity of developed word lists. It is generally expected that normal-hearing individuals usually obtain maximum SIS, i.e., $90-100 \%$ at levels of $30-40$ dBSL with reference to SRT $[10,11]$. As PTA and SRT are 
expected to be in good agreement in normal-hearing listeners [10], we used PTA was used as a reference value in the present study. The mean SIS of each group and overall group for four word-lists fell within the expected range of SIS, i.e., 90 to $100 \%$ at $40 \mathrm{dBSL}$ with reference to PTA. The study results are consistent with results from other Indian language research studies such as Kannada [12], Tamil [13], Punjabi [14], and Telugu [15]. The levels at which maximum scores were obtained in the present study therefore correspond well to levels reported for normal hearing children in the existing literature.

The speech identification performance can be assessed by the age of six in typically developing children [1]. Therefore, we aimed to develop an open-set speech identification test in Marathi to assess native children aged 6 to 8 years. The results revealed that the children obtained mean SIS of 99.15\%, $98.97 \%, 99.06 \%$, and $99.02 \%$ for four word-lists respectively, and were falling within the normal range (90 to 100\%). The speech identification performance of children primarily depends on the receptive and expressive language competencies as well as the children's auditory capabilities. We have performed a familiarity assessment of words to ensure that the words which are included in the four word-lists were familiar to children and were within children's receptive and expressive vocabulary. Hence, the children in the present study achieved speech identification performance that is comparable with adult-like performance. Similar arguments were made by Gupta [14] and Kumar \& Mohanty [15] who have developed speech identification tests for assessing children in Panjabi and Telugu languages respectively and reported speech identification performance that fell within the normal range (90-100\%).

\section{CONCLUSIONS}

The present study developed an open-set test in Marathi for assessing the speech identification performance of native children. The test consisted of four word-lists with each word list consisting of fifteen monosyllabic and ten disyllabic words. The SIS testing was performed on three groups of children. The results revealed that there was no significant difference between the mean SIS of three groups for each word list and between four word-lists for each group. The mean SIS of three groups were falling within the normal range. Thus, the four word-lists developed in the present study were found to be equally difficult, reliable, and valid test materials in Marathi for assessing native children. As the aim of the study was not to develop the normative, the sample size of the study was small. Further study is required to develop normative on a wider sample of children with normal-hearing of the respective language. Further, the applicability of the developed test materials can be checked by administering them on children with hearing impairment and other clinical populations. Besides, these materials can be used in selecting appropriate rehabilitative devices and also to measure the efficacy of different rehabilitative devices. The same test materials can be adapted to further develop the words-in-noise test, timecompressed speech test, filtered-speech test, and other special tests for differential diagnosis of auditory disorders in children.

\section{ACKNOWLEDGEMENTS}

The authors thank the following for their help in conducting this study. Students: Rasika, Yash, Madhura, Gunjan, Yash, Prajakta, and Rajashri. Colleagues: Dr. Medha Adhyaru, Dr. Rajiv R Jalvi, Dr. Aparna Nandurkar, Dr. Anjali Kant, Mrs. Jyothi Mohite, Mrs. Alpana Pagare, and Mrs. Pranjali Anand Ujwane. The authors sincerely thank Mrs. Mayuri S. Kulkarni (Tarang Speech and Hearing Center) and Mr. Yash Rajiv Huzurbazar (Sanwad Speech and Hearing Center) for their constant support and cooperation in carrying out SIS testing.

\section{REFERENCES}

1. Gelfand SA. Essentials of audiology. 2nd Ed. New York: Thieme Medical Publishers; 2008.

2. Mendel LL. Considerations in pediatric audiology. International Journal of Audiology. 2008;47:546-553.

3. Kumar SBR, Mohanty P, Ujwane PA, Huzurbazar YR. Conventional speech identification test in marathi for adults. International Journal of Otorhinolaryngology and Head and Neck Surgery. 2016;2:205-215.

4. Hirsh IJ, Davis H, Silverman SR, Reynolds EG, Eldert E, Benson RW. Development of materials for speech audiometry. Journal of Speech and Hearing Research. 1952;17:321-337.

5. Martin FN, Champlin CA, Perez DD. The question of phonetic balance in word recognition testing. Journal of American Academy of Audiology. 2000;11:489-493.

6. Kumar SBR, Mohanty P. Speech recognition performance of adults: a proposal for a battery for telugu. Theory and Practice in Language Studies. 2012a;2:193-204.

7. Stevens KN. Toward a model for lexical access based on acoustic landmarks. Journal of Acoustic Society of America. 2002;111: 1872-1891.

8. Manjula P, Antony J, Kumar KSS, Geetha C. Development of pho- 
nemically balanced word lists for adults in the Kannada language. Journal of Hearing Sciences. 2015;5:22-30.

9. Mendel LL, Danhauer JL. Audiologic evaluation and management and speech perception assessment. San Diego: Singular Publishing Company; 1997.

10. Brandy W. Speech audiometry. In handbook of clinical audiology: fifth edition, edited by J. Katz, 96-110. Philadelphia: Lippincott Williams \& Wilkins; 2002.

11. McArdle R, Hnath-Chisolm T. Speech audiometry. In: handbook of clinical audiology, edited by J. Katz, 61-75. Philadelphia: Wolters Kluwer; 2015.
12. Vandana S. Speech identification test for kannada speaking children. Unpublished Master's Independent Project. Mysore: University of Mysore; 1998.

13. Prakash B. A Picture speech identification test for children in tamil. Unpublished Master's Independent Project. Mysore: University of Mysore; 2000.

14. Gupta G. Development of speech material for punjabi speaking children. Unpublished Master's Dissertation, Hyderabad: Osmania University; 2011.

15. Kumar SBR, Mohanty P. Speech recognition performance by children: a battery for telugu. Indian Linguistics. 2012b;73:101-115. 
Appendix I

The word lists for assessing speech identification performance of children in Marathi

\begin{tabular}{|c|c|c|c|c|c|c|c|}
\hline \multicolumn{2}{|c|}{ List 1} & \multicolumn{2}{|c|}{ List 2} & \multicolumn{2}{|c|}{ List 3} & \multicolumn{2}{|c|}{ List 4} \\
\hline पाटी & pati & पाणी & pani & गाय & ga:j & घर & $\mathbf{g}^{\mathrm{h} \partial r}$ \\
\hline गाय & ga:j & घर & $\mathbf{g}^{\mathrm{h}} \partial \mathrm{r}$ & दात & dat & डास & da:s \\
\hline बस & bəs & टोपी & topi & नाव & na:w & गाव & ga:w \\
\hline दात & dat & डास & da:s & जीभ & dzi: $b^{h}$ & पाय & pa:j \\
\hline फळ & $p^{h} \partial l$ & खोली & $k^{h}$ oli & मीठ & $\mathrm{mit}^{\mathrm{h}}$ & राजा & $\operatorname{rad} 3 a$ \\
\hline नाव & na:w & गाव & ga:w & रोज & rodz & दूर & dur \\
\hline ताट & ta:t & भूक & $b^{h} \mathbf{u}: k$ & मोर & mor & तवा & təwa \\
\hline जीभ & $d 3^{i}: b^{h}$ & पाय & pa:j & वेणी & veni & डोके & dole \\
\hline खीर & $k^{h^{i r}}$ & वास & wa:s & दोरा & dora & तीन & tị:n \\
\hline मीठ & $\mathrm{mit}^{\mathrm{h}}$ & राजा & radza & वडा & vəda & मोठा & $\operatorname{mot}^{h} a$ \\
\hline शाळा & Jala & हात & ha:t & घोडा & $g^{\mathrm{h}}$ oda & ढग & $d^{h} \partial g$ \\
\hline रोज & rodz & दूर & dur & गाल & ga:I & माशी & maji \\
\hline साप & sa:p & फूल & $p^{h} u: I$ & पाटी & pati & पाणी & pani \\
\hline मोर & mor & तवा & țwa & बस & bəs & दूध & dud $^{h}$ \\
\hline कधी & $\mathbf{k} \mathbf{d}^{h_{i}}$ & कान & ka:n & कडू & kədu & टोपी & topi \\
\hline वेणी & veni & डोळे & dole & फळ & $\mathbf{p}^{\mathrm{h}}$ əl & खोली & $k^{\mathrm{h}}$ oli \\
\hline पुढे & $p U q^{h} e$ & बोट & bot & ताट & ta:t & भूक & $b^{h} u: k$ \\
\hline दोरा & dora & तीन & tị:n & खीर & $k^{h^{h}}$ ir & वास & wa:s \\
\hline चहा & toha & जाड & dzad & शाळा & Jala & हात & ha:t \\
\hline वडा & vəda & मोठा & $\operatorname{mot}^{\mathrm{h}} a$ & साप & sa:p & फूल & $p^{h} u: I$ \\
\hline तेल & te:l & चोर & tsor & कधी & $\mathbf{k} \mathbf{d}^{h^{h}} \mathbf{i}$ & कान & ka:n \\
\hline घोडा & $g^{\mathrm{h}}$ oda & ढग & $d^{h} \partial g$ & पुढे & $p^{\prime} q^{h} e$ & बोट & bot \\
\hline नाक & na:k & काळा & kala & चहा & toha & जाड & dzad \\
\hline गाल & ga:I & माशी & maji & तेल & te:l & चोर & tsor \\
\hline कडू & kədu & दूध & dud $^{h}$ & नाक & na:k & काळा & kala \\
\hline
\end{tabular}

In Marathi the letter ' $\bar{y}$ ' represents [t] and [ts], and the letter ' $v$ ' represents [dz] and [dz]. However, there are no separate letters for [t] and [ts], [dz] and [dz] in Marathi. The phonemes $[t]$ and $[t s]$ are represented by the letter ' $z$ ' and the phonemes [dz] and [dz] are represented by the letter ' $ज$ '. Hence, they are represented as ' $\bar{y}$ ' and ' $ज$ ' in the word lists. 